\title{
KENDALI ROBOT LENGAN 4 DOF BERBASIS ARDUINO UNO DAN SENSOR MPU-6050
}

\author{
Bagus Utomo \\ Fakultas Teknik, Program Studi Teknik Elektro \\ Universitas Muria Kudus \\ Email: bagusutomo0301@gmail.com
}

\author{
Noor Yulita Dwi Setyaningasih, S.T., M.Eng. \\ Fakultas Teknik, Program Studi Teknik Elektro \\ Universitas Muria Kudus \\ Email: noor.yulita@umk.ac.id \\ Mohammad Iqbal, S.T., M.T. \\ Fakultas Teknik, Program Studi Teknik Elektro \\ Universitas Muria Kudus \\ Email: mohammad.iqbal@umk.ac.id
}

\begin{abstract}
ABSTRAK
Dimasa sekarang ini robot banyak digunakan dalam berbagai bidang kehidupan, terdapat berbagai jenis robot yang dikembangkan salah satunya adalah robot lengan karena memiliki fungsi yang sama dengan lengan manusia. Salah satu kendala dalam pengoperasian robot adalah karena kebanyakan robot memerlukan pemrograman terlebih dahulu untuk mengoperasikan sehingga sulit bagi orang awam. Tujuan dari penelitian ini adalah membuat sistem kendali lengan robot yang dapat mengendalikan lengan robot hanya dengan menggerakan tangan dan menekan tombol. Penelitian ini menggunakan sensor MPU-6050 sebagai sensor sudut dan potensiometer sebagai pengatur gerakan robot, selain itu juga menggunakan Arduino Uno sebagai pengolah masukan sensor agar dapat mengendalikan lengan robot. Adapun robot yang digunakan adalah robot lengan 4 DOF (Degree Of Freedom) dengan penggerak motor servo. Penelitian ini menggunakan metode research and development yaitu dengan mempelajari dan mengembangkan penelitian sebelumnya. Pengujian sensor MPU-6050 mendapatkan hasil dengan nilai error pembacaan sebesar $0,72 \%$ pada sumbu $\mathrm{X}$ dan $0,68 \%$ pada sumbu Y. Waktu yang dibutuhkan untuk sekali proses pemindahan barang adalah selama 3 detik. Hasil dari sistem yang telah dibuat, robot mampu memindahkan barang ketempat yang diinginkan. Tingkat keberhasilan proses pindah barang menggunakan robot lengan 4 DOF adalah $100 \%$.
\end{abstract}

Kata kunci: kendali; open loop; robot; MPU-6050; arduino; potensiometer.

\section{ABSTRACT}

In today's robot is widely used in various fields of life, there are various types of robots developed, one of which is a robot arm because it has the same function as a human arm. One obstacle in the operation of robots is because most robots require programming in advance to operate so it is difficult for ordinary people. The purpose of this research is to create a robot arm control system that can control a robot arm just by moving the hand and pressing a button. This study uses the MPU-6050 sensor as an angle sensor and potentiometer as a regulator of robot motion, while also using Arduino Uno as a sensor input processor in order to control the robot arm. The robot used is the DOF (Degree of Freedom) 4-arm robot with servo motor drive. This research uses research and development methods, namely by studying and developing previous research. MPU-6050 sensor test results with a reading error value of $0.72 \%$ on the $X$ axis and $0.68 \%$ on the $Y$ axis. The time required for one process of moving goods is for 3 seconds. The results of the system that has been made, the robot is able to move goods to the desired place. The success rate of moving goods using the robot arm 4 DOF is $100 \%$.

Keywords: control; open loop; robot; MPU-6050; arduino; potentiometer.

\section{PENDAHULUAN}

Pada masa sekarang ini teknologi robot sudah sangat berkembang dalam berbagai lini kehidupan sebagaimana tujuanya adalah untuk memudahkan pekerjaan manusia, teknologi robot sudah merambah berbagai bidang mulai dari bidang militer, perkantoran, industri, kesehatan atau medis bahkan dunia 
hiburan. Dalam dunia industri misalnya, robot di gunakan dalam berbagai bidang salah satunya adalah untuk memindah barang, memasang komponen pada peralatan elektronik dan lain-lain sebagainya, adapun keunggulan dari penggunaan lengan robot adalah memiliki keakuratan yang tinggi dan kemampuan untuk bekerja secara kontinyu dan stabil [1].

Salah satu jenis robot yang banyak digunakan dan mempunyai manfaat yang besar adalah robot lengan. Seperti layaknya fungsi lengan pada manusia robot lengan juga dapat diprogram untuk melakukan pekerjaan manusia seperti memindahkan barang dan mengangkat barang, bahkan dengan beban yang melebihi kemampuan manusia normal tergantung dari spesifikasi dari robot tersebut [2][3].

Hal yang utama dari sebuah robot dalam terutama robot lengan adalah sistem kendalinya, banyak robot yang dibuat dengan sistem kendali yang berbeda dan kelebihan dan kekurangan masing-masing seperti peneltian yang dilakukan Zambarkah yaitu membuat kendali lengan robot dengan sensor MPU6050 dengan hasil yang belum digunakan untuk melakukan satu kegiatan yang aplikatif[4][5][6].

Pada umumnya proses kendali lengan robot dilakukan dengan cara pemrograman terhadap lengan robot menggunakan bahasa pemrograman, hal tersebut tentunya sulit terutama bagi orang awam yang tidak menguasai pemrograman. Maka dari itu dalam pengendalian lengan robot agar lebih mudah maka dibuatlah penelitian yang berjudul "Rancang Bangun Kendali Robot Lengan 4 DOF Berbasis Arduino Uno Dan Sensor Mpu-6050". Nantinya dalam mengoperasikan lengan robot dapat dilakukan dengan mudah sebagaimana menggunakan tangan, dengan cara membuat alat kendali berupa sarung tangan yang dipasangi sensor MPU-6050 sebagai sensor sudut atau sensor Accelerometer sehingga dengan menggerakan tangan dengan sudut tertentu maka robot akan bergerak juga. Selain itu dipergunakan pula potensiometer yang dipasang pada sarung tangan dan akan dihubungkan dengan jari tangan sehingga jika jari tangan digerakan robot pun akan bergerak sesuai fungsi yang telah ditentukan. Robot tersebut nantinya akan diaplikasikan untuk memindahkan barang secara berulang, Dengan pusat kendali berada ditangan sehingga proses kendali robot dapat dilakukan dengan lebih mudah. Dengan adanya alat ini penulis berharap dapat bermanfaat bagi kemajuan dunia sistem kendali dan robotika. Selain itu juga dapat memudahkan pekerjaan manusia terutama yang berkaitan dengan robot lengan[7][8][9].

\section{METODOLOGI PENELITIAN}

Pada penelitian ini menggunakan metode penelitian "Research And Development / R\&D" (penelitian dan pengembangan) artinya dengan mempelajari dan mengembangkan penelitian yang sudah ada. Adapun alur yan digunakan pada penelitian rancang bangun kendali robot lengan 4 dof berbasis arduino uno dan sensor mpu-6050 adalah mulai dari studi literatur melalui jurnal dan buku mengenai penelitian terkait, perancangan hardware, perancangan software, perancangan prototype, pengujian prototype, dan setelah jadi jika prototype dirasa belum berfungsi dengan baik maka akan dilaukan evaluasi dari tahapan sebelumnya, setelah prototype dapat berfungsi dengan baik maka tahap selanjutnya adalah pengambilan data, dan pengujian data. Semua tahapan tersebut harus dilakukan dengan sistematis dan runtut agar didapat hasil yang diinginkan.

\subsection{Perancangan Desain Prototipe}

Pada perancangan desain prototipe ini, meliputi desain lengan seperti pada Gambar 1, dan desain rangaka sarung tangan seperti pada Gambar 2 desain tersebut selanjutanya dibuat menjadi benda asli menggunakan teknologi printer 3D.

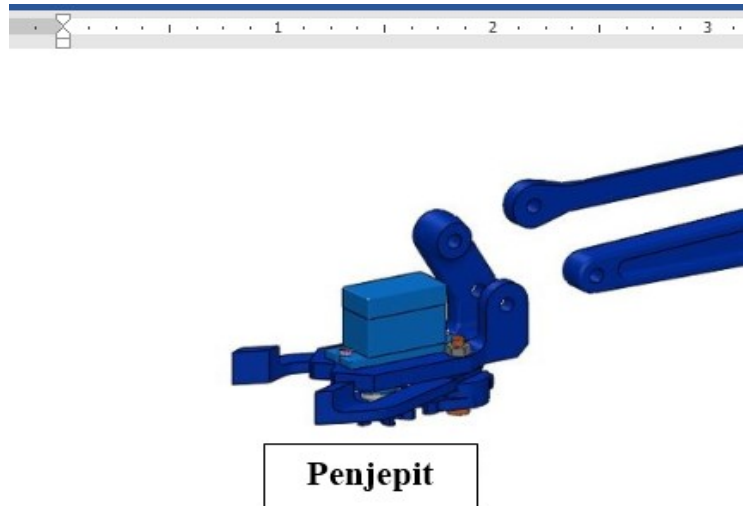

Gambar 1. Desain Lengan Robot [10] 


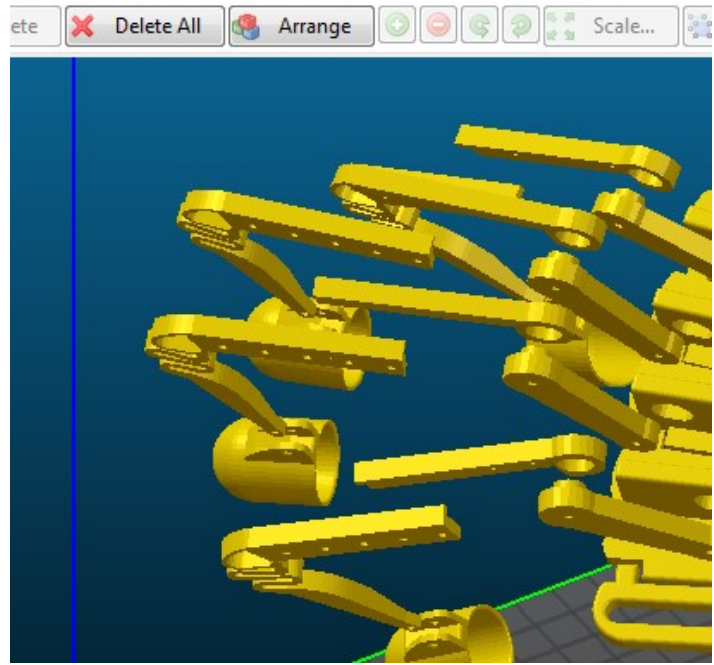

\section{Gambar 2. Desain Rangka Sarug Tangan [11]}

Setelah lengan robot dan rangka sarung tangan jadi maka tahap selanjutnya adalah menyatukan dengan komponen elektronik berupa motor servo dan potensiometer.

\subsection{Perancangan Hardware}

Perancangan hardware dari sistem ini terdiri dari perancangan komponen elektronika dan penyesuaian komponen yang akan digunakan. Untuk lebih jelasnya bisa lihat pada Gambar 3.

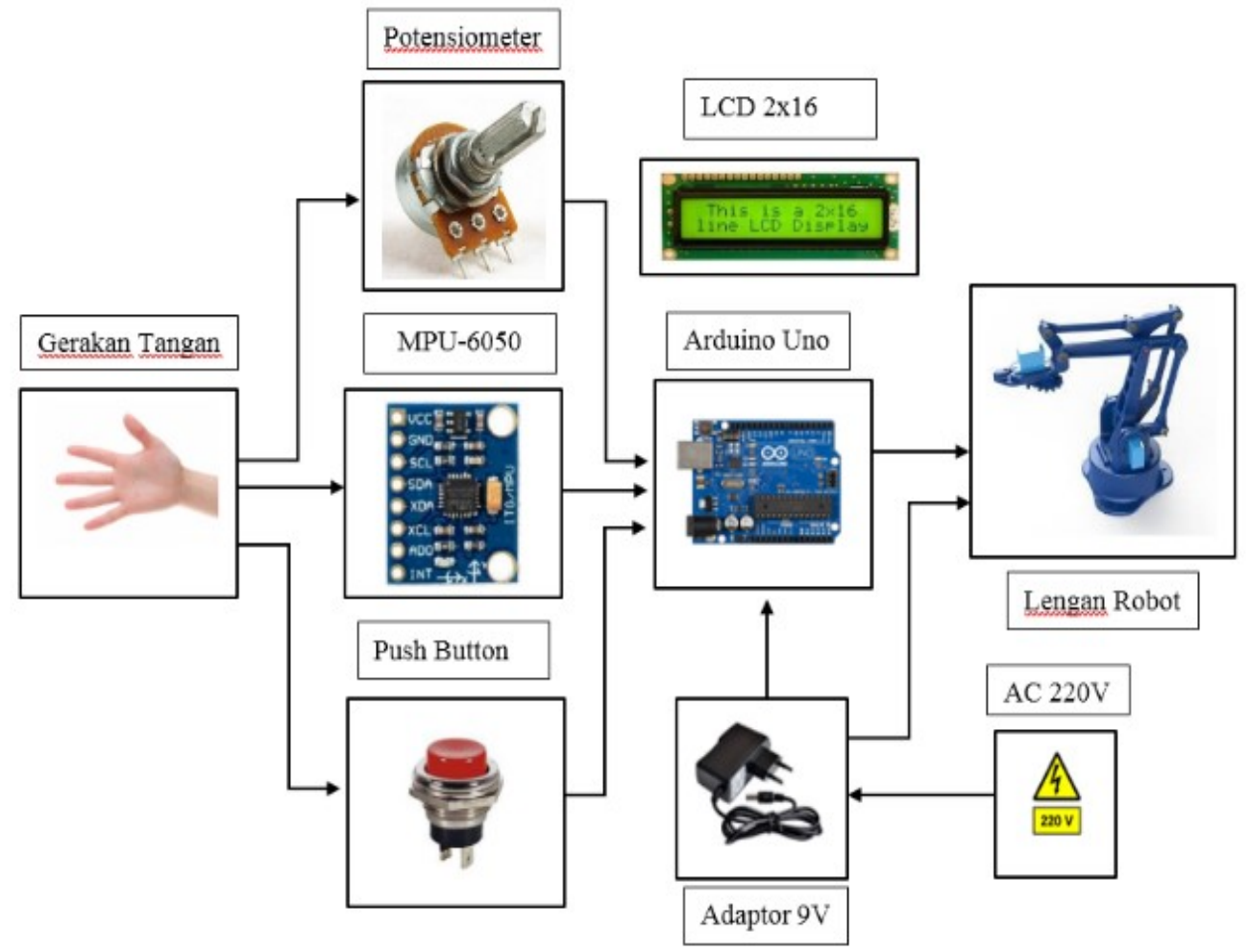

Gambar 1. Perancangan Hardware

Perancangan hardware disini meliputi yang pertama ada arduino uno sebagai pusat pengolah perintah, sensor MPU-6050 sebagai sensor Accelerometer yaitu sebagi masukan pada arduino uno untuk mengendalikan lengan robot, potensiometer digunakan sebagai masukan pada arduino untuk kendali lengan robot, push button digunakan sebagai masukan untuk arduino untuk save dan play perintah pada lengan robot, dan yang terakhir adalah motor servo yaitu sebagai penggerak dari lengan robot. 


\subsection{Perancangan Software}

Perancangan software ini menggunakan program Arduino IDE versi 1.8.5 yang sudah dipasang di PC. Yang dapat dilihat pada Gambar 4.

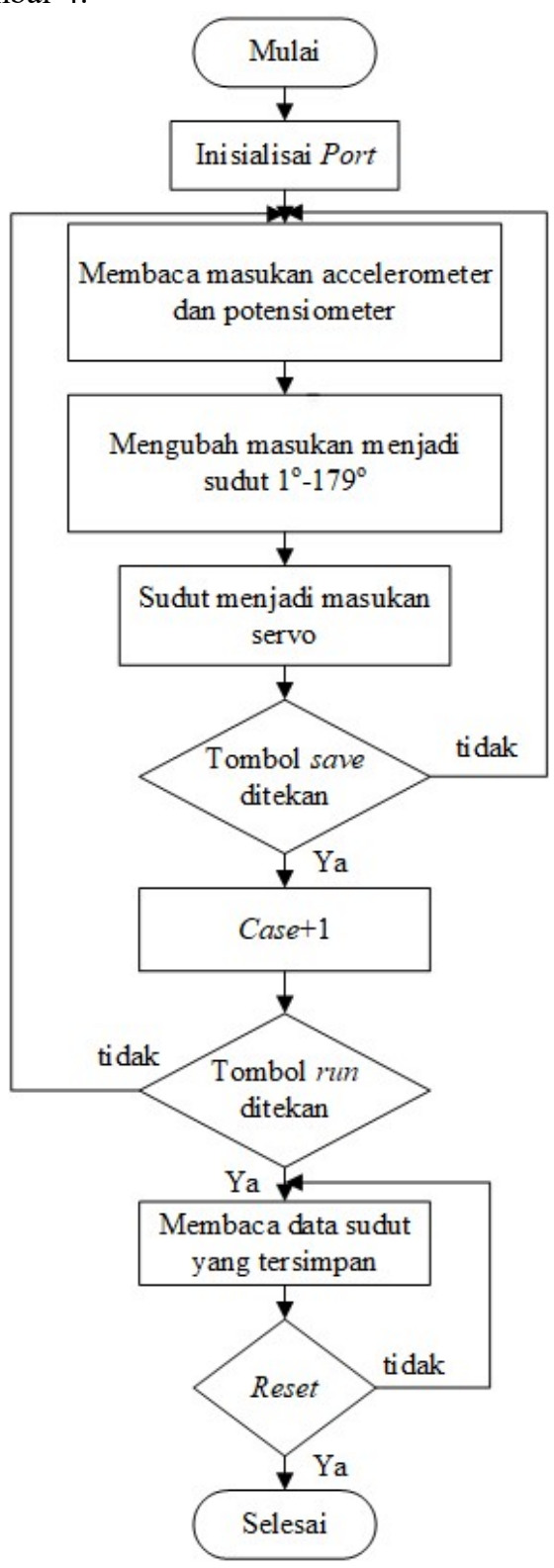

Gambar 2. Perancangan Software

Alur sistem kendali dimulai dari inisialisasi port, membaca input dari sensor MPU-6050 dan potensiometer, masukan tersebut akan digunakan sebagai pengatur sudut putaran dari masing-masing servo pada robot lengan, jika gerakan sudah sesuai yang diinginkan maka langkah selanjutnya adalah merekam gerakan tersebut dengan menekan tombol save maka gerakan tersebut akan tersimpan ke case 1 kemudian secara otomatis akan ber alih ke case berikutnya sampai jumlah case yang ditentukan dalm penelitian ini maksimal 8 case. Langkah selanjutnya adalah menekan tombol run untuk menjalankan gerakan yang sudah di simpan. Setelah itu robot lengan akan bekerja secara otomatis sampai dihentikan dengan Reset program atau aliran listrik di cabut.

\subsection{Skema Perancangan Alat}

Untuk skema perancangan alat, bisa dilihat pada Gambar 5: 


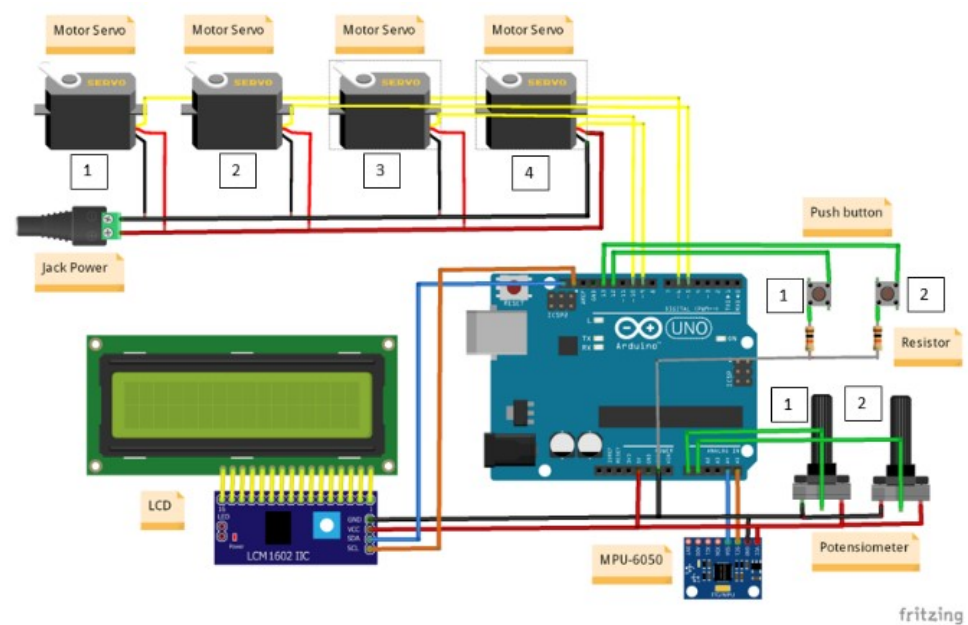

Gambar 3. Skema Perancangan Alat

Gambar 5 merupakan gambar skema rangkaian dari sistem kendali pada penelitian ini, yaitu terdiri dari 4 buah servo, 2 buah potensiometer, MPU-6050, LCD I2C, dan push button.

\section{HASIL DAN PEMBAHASAN}

\subsection{Pengujian Sensor MPU-6050}

Berikut merupakan proses pengujian sesor MPU-6050 pada Gambar 6.

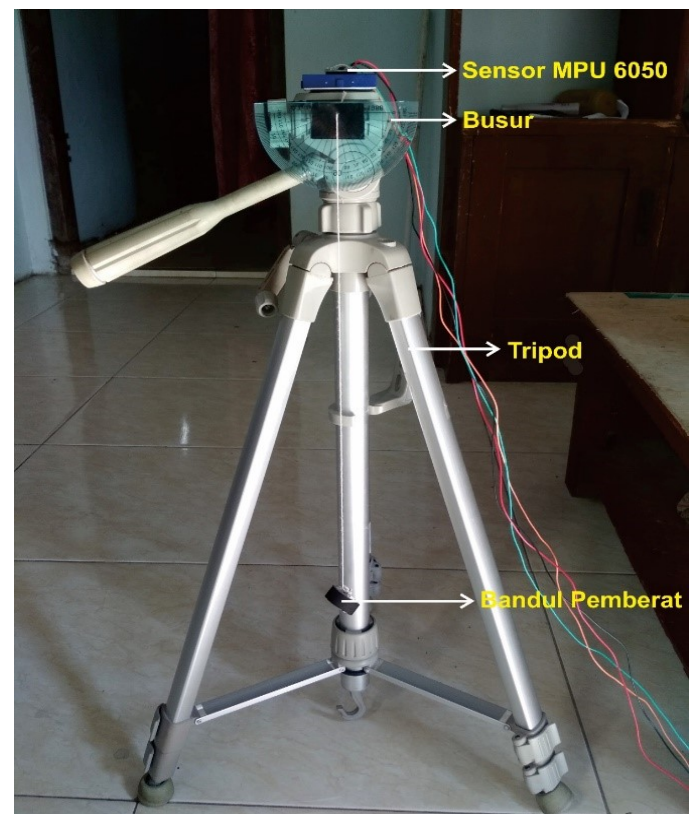

Gambar 6. Media Pengujian Sensor MPU-6050

Gambar 3.1 merupakan tampilan dari media pengujian sensor MPU-6050 yaitu menggunakan tripod sebagai penyangga, busur sebagai pengujur dusut, dan bandul dengan benang sebagi titik acuan sudut memanfaatkan gaya grafitasi dan hasil pembacaan dari sensor ditampilkan melalui serial monitor dan akan dibandingkan dengan sudut sebenarnya pembacaan dari busur untuk tabel pengujianya dapat dilihat pada Tabel 1 dan Tabel 2. 
Tabel 1. Perbandingan sudut pembacaan sensor dengan sudut sebenarnya pada sumbu $X$

\begin{tabular}{|c|c|c|c|c|c|c|}
\hline \multirow[t]{2}{*}{ No. } & \multirow{2}{*}{$\begin{array}{c}\text { Sudut Pada } \\
\text { Busur }\end{array}$} & \multicolumn{3}{|c|}{ Sudut Sumbu X Pada Sensor } & \multirow{2}{*}{$\begin{array}{c}\text { Sudut Rata-rata } \\
\text { Sensor }\end{array}$} & \multirow[t]{2}{*}{ Error \% } \\
\hline & & 1 & 2 & 3 & & \\
\hline 1. & $20^{\circ}$ & $20,17^{\circ}$ & $20,02^{\circ}$ & $20,09^{\circ}$ & $20,09^{\circ}$ & 0,45 \\
\hline 2. & $40^{\circ}$ & $40,11^{\circ}$ & $40,03^{\circ}$ & $40,07^{\circ}$ & $40,07^{\circ}$ & 0,17 \\
\hline 3. & $60^{\circ}$ & $61,41^{\circ}$ & $61,39^{\circ}$ & $61,31^{\circ}$ & $61,37^{\circ}$ & 2,18 \\
\hline 4. & $80^{\circ}$ & $80,47^{\circ}$ & $80,55^{\circ}$ & $80,6^{\circ}$ & $80,54^{\circ}$ & 0,75 \\
\hline 5. & $100^{\circ}$ & $98,74^{\circ}$ & $98,73^{\circ}$ & $98,75^{\circ}$ & $98,74^{\circ}$ & 1,25 \\
\hline 6. & $120^{\circ}$ & $120,57^{\circ}$ & $120,55^{\circ}$ & $120,6^{\circ}$ & $120,57^{\circ}$ & 0,5 \\
\hline 7. & $140^{\circ}$ & $141,4^{\circ}$ & $140,95^{\circ}$ & $140,9^{\circ}$ & $141,08^{\circ}$ & 0,64 \\
\hline 8. & $160^{\circ}$ & $160,7^{\circ}$ & $160,67^{\circ}$ & $160,73^{\circ}$ & $160,7^{\circ}$ & 0,45 \\
\hline 9. & $180^{\circ}$ & $180,03^{\circ}$ & $180,2^{\circ}$ & $180,19^{\circ}$ & $180,14^{\circ}$ & 0,10 \\
\hline \multicolumn{5}{|c|}{ Total Nilai Error Pengujian Data } & \multicolumn{2}{|c|}{$0,72 \%$} \\
\hline
\end{tabular}

Tabel 2. Perbandingan sudut pembacaan sensor dengan sudut sebenarnya pada sumbu $Y$

\begin{tabular}{|c|c|c|c|c|c|c|}
\hline \multirow[t]{2}{*}{ No. } & \multirow{2}{*}{$\begin{array}{c}\text { Sudut Pada } \\
\text { Busur }\end{array}$} & \multicolumn{3}{|c|}{ Sudut Sumbu Y Pada Sensor } & \multirow{2}{*}{$\begin{array}{c}\text { Sudut Rata-rata } \\
\text { Sensor }\end{array}$} & \multirow[t]{2}{*}{ Error \% } \\
\hline & & 1 & 2 & 3 & & \\
\hline 1. & $20^{\circ}$ & $20,15^{\circ}$ & $19,96^{\circ}$ & $19,97^{\circ}$ & $20,02^{\circ}$ & 0,13 \\
\hline 2. & $40^{\circ}$ & $39,32^{\circ}$ & $39,31^{\circ}$ & $39,2^{\circ}$ & $39,27^{\circ}$ & 1,80 \\
\hline 3. & $60^{\circ}$ & $59,21^{\circ}$ & $59,14^{\circ}$ & $15,16^{\circ}$ & $59,17^{\circ}$ & 1,38 \\
\hline 4. & $80^{\circ}$ & $80,21^{\circ}$ & $80,34^{\circ}$ & $80,4^{\circ}$ & $80,31^{\circ}$ & 0,39 \\
\hline 5. & $100^{\circ}$ & $100,71^{\circ}$ & $100,83^{\circ}$ & $100,92^{\circ}$ & $100,82^{\circ}$ & 0,82 \\
\hline 6. & $120^{\circ}$ & $120,71^{\circ}$ & $120,69^{\circ}$ & $120,71^{\circ}$ & $120,70^{\circ}$ & 0,58 \\
\hline 7. & $140^{\circ}$ & $140,19^{\circ}$ & $140,37^{\circ}$ & $140,4^{\circ}$ & $140,32^{\circ}$ & 0,22 \\
\hline 8. & $160^{\circ}$ & $160,41^{\circ}$ & $160,66^{\circ}$ & $160,63^{\circ}$ & $160,56^{\circ}$ & 0,35 \\
\hline 9. & $180^{\circ}$ & $180,88^{\circ}$ & $180,91^{\circ}$ & $180,96^{\circ}$ & $180,91^{\circ}$ & 0,50 \\
\hline \multicolumn{5}{|c|}{ Total Nilai Error Pengujian Data } & \multicolumn{2}{|l|}{$0,68 \%$} \\
\hline
\end{tabular}

Berdasarkan pengujan sensor MPU-6050 baik pada sumbu X maupun Y didapatkan hasil nilai rata-rata presentase error yang kecil yaitu $0,72 \%$ pada sumbu $\mathrm{X}$ dan $0,68 \%$ pada sumbu $\mathrm{Y}$. Berdasarkan hal tersebut sensor MPU-6050 yang digunakan dalam penelitian ini dalam kondisi yang baik untuk digunakan dalam sistem kendali lengan robot.

\subsection{Pengujian Potensiometer}

Potensiometer digunakan untuk mengendalikan gerakan robot maka dari itu potensiometer dipasang pada sarung tangan seperti pada Gambar 7.

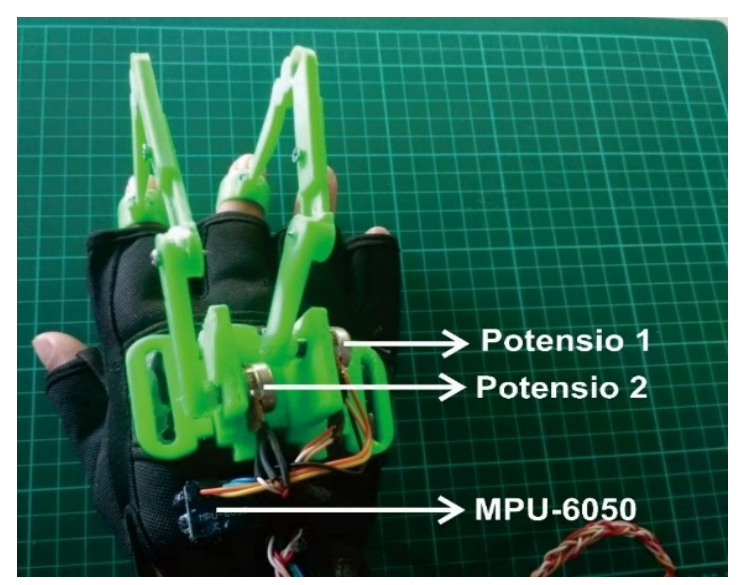

Gambar 7. Hasil Perakitan Sarung Tangan 
Setelah komponen elektronik terpasang pada sarung tangan maka dilanjutkan dengan pengujian tegangan output potensiometer. Dengan mengenakan sarung tangan dan digerakan untuk menggenggam dan membuka tangan seperti
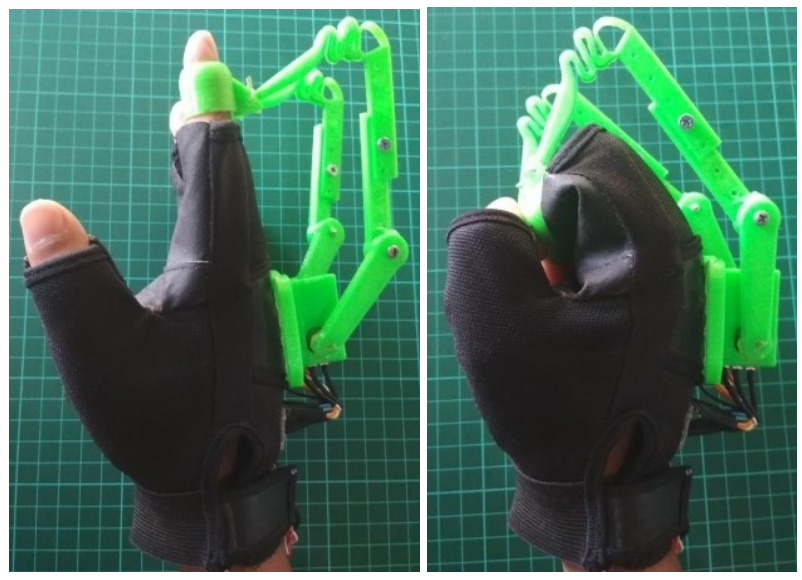

Gambar 8. Pengambilan Data Output Potensiometer

Pada Gambar 8, kemudian sarung tangan pada arduino. Kemudian output analog read dicatat dan digunkan untuk mapping servo. Maka servo yang digunakan untuk menggerakan robot akan bergerak mengikuti gerakan jari tangan. Dari pengujian ini didapat hasil seperti pada Tabel 3, hasil tersebut akan dimasukan dalam program kendali lengan robot.

Tabel 3. Data analog read output potensiometer

\begin{tabular}{|c|c|c|c|c|c|}
\hline \multirow[b]{2}{*}{ No. } & \multirow[b]{2}{*}{ Posisi Jari } & \multicolumn{3}{|c|}{ Nilai Analog Read } & \multirow[b]{2}{*}{ Rata-rata } \\
\hline & & $\begin{array}{c}\text { Percobaan } \\
1\end{array}$ & $\begin{array}{c}\text { Percobaan } \\
2\end{array}$ & $\begin{array}{c}\text { Percobaan } \\
3\end{array}$ & \\
\hline 1. & Jari Telunjuk lurus & 471 & 469 & 485 & 475 \\
\hline 2. & Jari Telunjuk mengepal & 256 & 256 & 257 & 256 \\
\hline 3. & Jari Tengah lurus & 514 & 514 & 513 & 514 \\
\hline 4. & Jari Tengah mengepal & 269 & 269 & 271 & 267 \\
\hline
\end{tabular}

jari telunjuk memiliki rentang antara 256 sampai 475 , dan pada jari tengah memiliki rentang antara 267 sampai 514

\subsection{Pengambilan data kendali robot}

Berikut merupakan hasil pengujian keseluruhan sistem yang meliputi pengujian kendali lenga robot dengan sensor accelerometer MPU-6050, pengujian kendali lenga robot dengan potensiometer, dan pengujian keseluruhan untuk memindahkan barang seperti pada Gambar 9. Adapun hasilnya dapat dilihat pada Tabel 4.

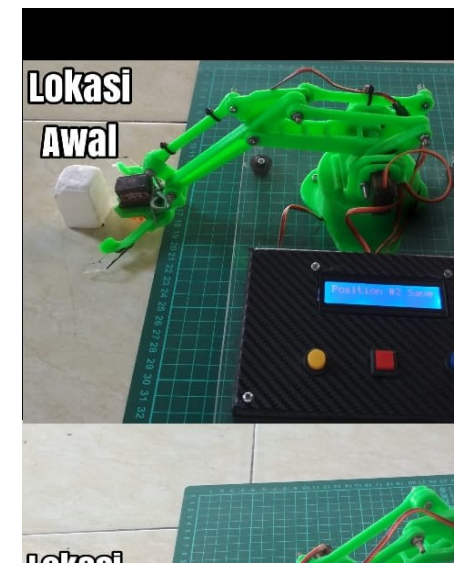

Gambar 9. Pengujian Memindahkan Barang 
Tabel 4. Hasil pengujian kendali lengan robot memindahkan barang

\begin{tabular}{clccc}
\hline \multirow{2}{*}{ No. } & \multicolumn{1}{c}{ Posisi tangan dan pergerakan } & \multicolumn{3}{c}{ Respon gerakan robot } \\
robot & Pengujian1 & Pengujian2 & Pengujian3 \\
\hline 1. & $\begin{array}{l}\text { Gerakan tangan } 1 \\
\text { Awal Gerakan robot }\end{array}$ & Sesuai & Sesuai & Sesuai \\
2. & $\begin{array}{l}\text { Gerakan tangan } 2 \\
\text { Robot bergerak ke kanan }\end{array}$ & Sesuai & Sesuai & Sesuai \\
3. $\quad \begin{array}{l}\text { Gerakan tangan } 3 \\
\text { Robot bergerak maju dan turun }\end{array}$ & Sesuai & Sesuai & Sesuai \\
4. $\quad \begin{array}{l}\text { Gerakan tangan } 4 \\
\text { Robot mencengkram benda }\end{array}$ & Sesuai & Sesuai & Sesuai \\
5. $\quad \begin{array}{l}\text { Grakan tangan } 5 \\
\text { Robot bergerak naik }\end{array}$ & Sesuai & Sesuai & Sesuai \\
6. $\quad \begin{array}{l}\text { Gerakan tangan } 6 \\
\text { Robot bergerak ke kiri }\end{array}$ & Sesuai & Sesuai & Sesuai \\
7. & $\begin{array}{l}\text { Gerakan tangan } 7 \\
\text { Robot bergerak maju dan turun }\end{array}$ & Sesuai & Sesuai & Sesuai \\
8. & $\begin{array}{l}\text { Robot meletakan benda } \\
\text { Robongan } 8\end{array}$ & Sesuai & Sesuai & Sesuai \\
\hline
\end{tabular}

Dari hasi pengujian memindahkan barang sebanyak 3 kali pengujian didapatkan nilai keberhasilan sebesar $100 \%$ karena semua gerakan sarung tangan sama dengan gerakan lengan robot .

\section{KESIMPULAN}

a. Hasil yang diperoleh dari penelitian ini adalah terciptanya prototype kendali robot lengan 4 dof berbasis arduino uno dan sensor mpu-6050.

b. Pengujian sensor MPU-6050 mendapatkan hasil dengan nilai error pembacaan sebesar 0,72\% pada sumbu X dan $0,68 \%$ pada sumbu Y.

c. Konversi gerakan jari telunjuk dan jari tengah menggunakan potensiometer untukmenggerakan lengan robot dapat diproses oleh sistem dengan tingkat keberhasilan $100 \%$.

d. Proses kendali lengan robot untuk memindahkan barang dapat berjalan dengan tingkat keberhasilan $100 \%$.

e. Kendali lengan robot melalui gerakan tangan akan lebih praktis yaitu dengan mengerakan sarung tangan dan menekan tombol, dibandingkan dengan melukan kendali dengan proses pemrograman.

\section{DAFTAR PUSTAKA}

[1] A. Saifuddin, Sumardi, and Darjat, "Perancangan Sistem Kendali Pergerakan Arm Manipulator Berbasis Sensor Inertial Measurement Unit ( Imu ) Dan Sensor Flex," Transient, vol. 6, no. 3, pp. 424-431, 2017.

[2] H. D. Siswaja, "Prinsip Kerja dan Klasifikasi Robot," Media Inform., vol. 7, no. 3, pp. 147-157, 2008.

[3] R. Syam, "Kinematika dan Dinamika Robot Lengan,” in Seri Buku Ajar Robotika, 2015, p. 76.

[4] A. Zambarkah, N. Salahuddin, and S. Sari, "Gyroscope Untuk Menggerakkan," J. Ilm. Komputasi, vol. 16, no. 3, pp. 1-6, 2017.

[5] R. Chandra, "Perancangan Lengan Robot Dengan Micro Servo Berbasis Arduino Uno," no. February. p. 5, 2017.

[6] A. Triwiyatno, "Konsep Umum Sistem Kontrol," Buku Ajar Siste Kontrol Analog. pp. 1-11, 2011.

[7] M. Didi, E. D. Marindani, and A. Elbani, "Rancang Bangun Pengendalian Robot Lengan 4 DOF dengan GUI ( Graphical User Interface ) Berbasis Arduino Uno I-2.” pp. 1-11, 2006.

[8] F. Supegina and D. Sukindar, "Perancangan Robot Pencapit Untuk Penyotir Barang Berdasarkan Warna Led Rgb Dengan Display Led Berbasis Arduino Uno," Tek. Elektro, Univ. Mercu Buana, vol. 5, no. 1, pp. 9-17, 2014.

[9] P. Prasetyawan, Y. Ferdianto, S. Ahdan, and F. Trisnawati, "Pengendali Lengan Robot Dengan Mikrokontroler Arduino Berbasis Smartphone," vol. 7, no. 2, pp. 104-109, 2018.

[10] DaGHIZmo, "EEZYbotARM," [Online]. $2015 . \quad$ Available: https://www.thingiverse.com/thing:1015238. [Accessed: 07-Aug-2019].

[11] Hatsyflatsy, "Potentiometer Servo Controller Glove," 2018. [Online]. Available: https://www.thingiverse.com/thing:2782111. [Accessed: 07-Aug-2019]. 